\title{
Effect of positioning on the accuracy of decision making of association football top-class referees and assistant referees during competitive matches
}

\author{
JAVIER MALLO, PABLO GONZALEZ FRUTOS, DANIEL JUÁREZ, \& ENRIQUE NAVARRO \\ Biomechanics Laboratory, Faculty of Physical Activity and Sport Sciences, Technical University of Madrid, Madrid, Spain
}

(Accepted 9 fuly 2012)

\begin{abstract}
The aim of this study was to examine the effect of positioning on the correctness of decision making of top-class referees and assistant referees during international games. Match analyses were carried out during the Fédération Internationale de Football Association (FIFA) Confederations Cup 2009 and 380 foul play incidents and 165 offside situations were examined. The error percentage for the referees when indicating the incidents averaged $14 \%$. The lowest error percentage occurred in the central area of the field, where the collaboration of the assistant referee is limited, and was achieved when indicating the incidents from a distance of $11-15 \mathrm{~m}$, whereas this percentage peaked (23\%) in the last 15-min match period. The error rate for the assistant referees was $13 \%$. Distance of the assistant referee to the offside line did not have an impact on the quality of the offside decision. The risk of making incorrect decisions was reduced when the assistant referees viewed the offside situations from an angle between 46 and $60^{\circ}$. Incorrect offside decisions occurred twice as often in the second as in the first half of the games. Perceptual-cognitive training sessions specific to the requirements of the game should be implemented in the weekly schedule of football officials to reduce the overall error rate.
\end{abstract}

Keywords: soccer, technical performance, distance to incidents, match analysis, offside

\section{Introduction}

The physical demands imposed on top-class football referees have been extensively evaluated over the last decade (Castagna, Abt, \& D'Ottavio, 2007; D'Ottavio \& Castagna, 2001; Krustrup \& Bangsbo, 2001; Krustrup et al., 2009; Mallo, Navarro, GarciaAranda, Gilis, \& Helsen, 2007; Mallo, Navarro, Garcia-Aranda, \& Helsen, 2009a; Weston, Castagna, Helsen, \& Impellizzeri, 2009). From these studies it has been concluded that referees cover around 10 $12 \mathrm{~km}$ during a competitive match with around 10$15 \%$ of the distance covered by high-speed activities (running faster than $18 \mathrm{~km} \cdot \mathrm{h}^{-1}$ ). Match distance covered by assistant referees averages $6-7 \mathrm{~km}$, with $15-20 \%$ of this running at high-speed (Krustrup, Mohr, \& Bangsbo, 2002; Krustrup et al., 2009; Mallo, Navarro, Garcia-Aranda, Gilis, \& Helsen, 2008; Mallo, Navarro, Garcia-Aranda, \& Helsen, 2009b).

Despite the abundant available data in the literature regarding the physical demands of officiating, less is known about the technical aspects of refereeing. The main task of referees during a match is to safeguard the application of the Laws of the Game (Fédération Internationale de Football Association [FIFA], 1993). For this purpose, an optimal positioning on the field of play seems crucial (Rontoyannis, Stalikas, Sarros, \& Vlastaris, 1998). Previous studies have examined the distance of the referees to the foul play incidents and have determined that this distance might be influenced by the zone in the field where the incident occurs, the time of the match when they are awarded and the fitness status of the referees (Krustrup \& Bangsbo, 2001; Krustrup et al., 2009; Mallo et al., 2007, 2009a; Weston et al., 2009). At the same time as adopting a good location in the field of play, it is essential for the officials to take the correct decision. Helsen and Bultynck (2004) determined that during an international match a referee takes around 140 observable decisions, with an average of 41 foul play incidents awarded per match. To our knowledge, it remains uncertain to what extent the distance of the referee to the incident would affect the quality of the decision. It would be expected that being too close to the foul play would compromise the ability of the referee to 
view and analyse the entire sequence. On the other hand, being far away could raise the risk of incurring errors as the play would not be seen with sufficient clarity.

Assistant referees play a supportive role for referees to judge the play and, specifically, to detect the offside positions of the attacking players. For this reason they are encouraged to follow the offside line throughout the game, a theoretical line determined at every moment by the position of the second-last defending player of each team and orthogonal to the sideline. Distance of the assistant referee to the offside line has been evaluated in several studies as a criterion to express the ability to keep up with the play (Catteeuw, Gilis, Wagemens, \& Helsen, 2010a; Catteeuw et al., 2010b; Krustrup et al., 2002; Helsen, Gilis, \& Weston, 2006; Mallo et al., 2008, $2009 \mathrm{~b})$. In addition to being close to the offside line, the assistant referees need to adopt a critical angle of view from the play to judge the possible offside situations of the attackers at the moment the ball touches or is played by one of their teammates. Catteeuw et al. (2010a) calculated the viewing angle of the assistant referee from the passer to the secondlast defender. However, this criterion may have led to underestimations during offside situations, as the positions of the attacking players are also needed to be perceived by assistant referees. It would be expected that, the wider this angle would be (balloffside line/attacker) the greater difficulties the assistant referee would have to judge the situation (Belda Maruenda, 2004; Sanabria et al., 1998). Both the distance to the offside line and the angle of view have been suggested to be two key factors when assistant referees take incorrect decisions (Oudejans et al., 2000, 2005).

Thus, the aim of this study was to examine the effect of positioning on the accuracy of decision making of referees and assistant referees during an elite senior FIFA tournament. Our hypothesis was that the correctness of the referees and assistant referees' decisions would be affected by the distance and angle of view adopted to follow the play.

\section{Methods}

\section{Participants}

Ten top-class referees (mean age 39.4 years, $s=2.4$; stature $182.5 \mathrm{~cm}, s=5.9$, and body mass $78.4 \mathrm{~kg}$, $s=4.6$ ) and 20 top-class assistant referees (mean age 37.3 years, $s=4.0$; stature: $178.2 \mathrm{~cm}, s=7.1$, and body mass: $74.7 \mathrm{~kg}, s=7.9$ ) participated in the study. All the officials had held FIFA licenses for 9.2, $s=4.1$ (in the case of referees) and 5.8, $s=3.8$ (assistant referees) years at international standard. Written consent from the Referees' Department and from all the participants was obtained before the beginning of the tournament, following an explanation of the nature of the research. This investigation was led in accordance with the local Institutional Review Board.

\section{Match analysis}

The study was conducted during the FIFA Confederations Cup held in South Africa in June 2009. Fifteen matches were filmed at $25 \mathrm{~Hz}$ using three fixed digital videocameras positioned in the main stand of the stadiums. The field of play was measured using a laser system (Leica Disto D5, Instop, Barcelona, Spain) with a precision of $1 \mathrm{~mm}$. A 12-point calibration system was developed for the frames obtained from each of the cameras. Previous research (Mallo et al., 2007) has reported a Root Mean Square error when using this method for reconstructing distances of less than $2 \%$.

All the foul play incidents $(n=380)$ that were awarded by the referee (direct and indirect freekicks) in each match were captured and digitised to determine, using two-dimensional Direct Lineal Transformation (DLT)-based algorithms, the position of the referee, assistant referee, offender (player who committed the infringement) and victim (player who received the infringement). The distance of the referee to the incident was calculated and, based on the findings of previous studies using the same methodology (Mallo et al., 2007, 2009; Mallo, Veiga, López de Subijana, \& Navarro, 2010), classified into the following categories: (i) $<5 \mathrm{~m}$; (ii) 6-10 m; (iii) $11-15 \mathrm{~m}$; (iv) $16-20 \mathrm{~m}$; (v) $21-$ $25 \mathrm{~m}$ and (vi) $>25 \mathrm{~m}$. Following suggestions from FIFA's Referees' Department the incidents were classified according to the area of the field where they were awarded (Figure 1). The lateral areas were determined tracing an imaginary line from the intersection between the central and sidelines and the middle point of the goal mouth, representing the influence zone of each assistant referee. The remaining area of the ground (central) is the zone that referees are encouraged to cover using diagonal

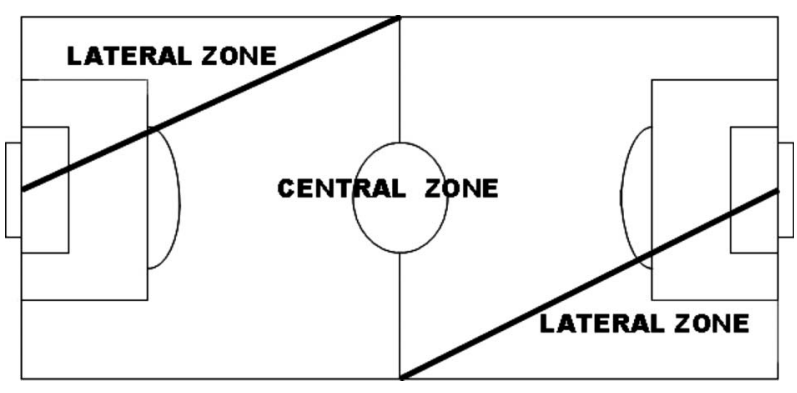

Figure 1. Zones into which the field of play was divided to analyse distance from incidents. 
movements during the games. Additionally, the incidents were computed throughout 15-min match periods for further analysis. To assess the correctness of the decisions taken during the matches, a FIFA panel of three top-class expert referees $(9.7, s=1.5$ years of experience at international standard) independently reviewed all the incidents from video footage which did not include any data (elapsed time, score, etc.) from the match. With the use of a video analysis system the experts were allowed to play and replay all the situations to decide whether the decision taken by the referee was correct or incorrect. Only the situations with complete agreement by the three experts were included in the study. To examine the intra-observer reliability of the viewing panel decisions, video footage of 50 foul plays was analysed twice by each expert with a two month interval, that is, before and after the data analysis. In addition, to assess the inter-observer reliability, the same video footage was analysed by the three experts before the commencement of the investigation. No significant differences $(P>0.05)$ were detected between observations for either reliability test.

The offside situations were captured and digitised at a frame rate of $50 \mathrm{~Hz}$ to calculate the positions of the assistant referee, ball and attacking and defending players involved in the play. Following the criterion proposed by Catteeuw et al. (2010a) we excluded from the analysis all the potential offside situations where the attacker was more than $2 \mathrm{~m}$ away from the second-last defender. The final number of offside situations examined was 165 . The horizontal distance between the attacker actively involved in the play and the offside line was calculated in order to examine if the assistant referee

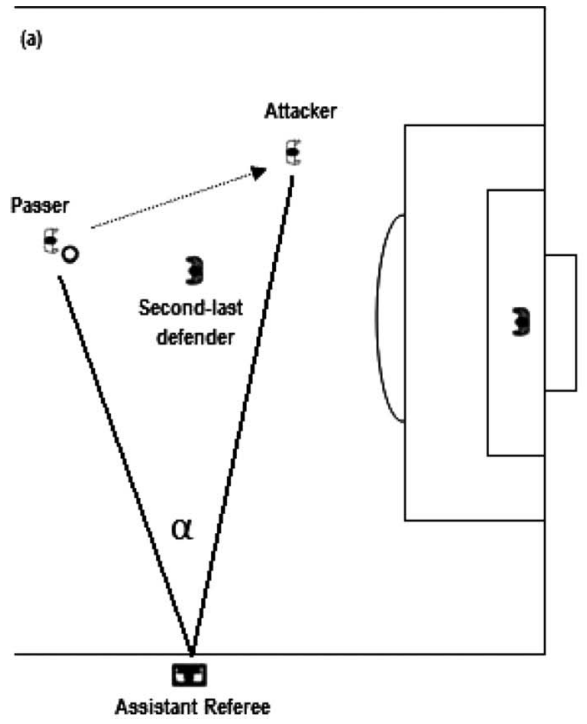

took a correct (player offside) or incorrect (player onside) decision. Using the same procedure, the horizontal distance from the assistant referee to the second-last defender was expressed as distance to the offside line. The assistants were considered to be in line when they were $20 \mathrm{~cm}$ or less from the offside line (Oudejans et al., 2005). The angle of view from the play was calculated from the position of the assistant referee to the ball and the attacking (Figure $2 \mathrm{a}$ ) or defending player (Figure $2 \mathrm{~b}$ ) closest to the attacking goal. The angle of view was categorised into: (i) $0-15^{\circ}$; (ii) $16-30^{\circ}$; (iii) $31-45^{\circ}$; (iv) $46-60^{\circ}$; (v) $61-75^{\circ}$ and (vi) $>75^{\circ}$. The time of play $(15-\mathrm{min}$ match periods) was also considered for further analysis. After Helsen et al. (2006) all the offside situations were classified into the following categories: (i) correct flag decision (the assistant referee raises the flag and the player is offside); (ii) flag error (the assistant referee raises the flag and the player is onside); (iii) correct non-flag decision (the assistant referee does not raise the flag and the player is onside) and (iv) non-flag error (the assistant referee does not raise the flag and the player is offside).

\section{Data analysis}

Data are presented as means and standard deviations of the mean $(s)$. Comparisons between two sets of data (45-min match periods, zone in the field where the foul plays were awarded and distance of the assistant referee to the offside line) were carried out using independent $t$-tests. 95\% Confidence Intervals (CI) were used to report mean differences between two sets of data. Differences between more than two sets of data within $15-\mathrm{min}$ match periods were tested using analysis of variance (ANOVA). To examine the

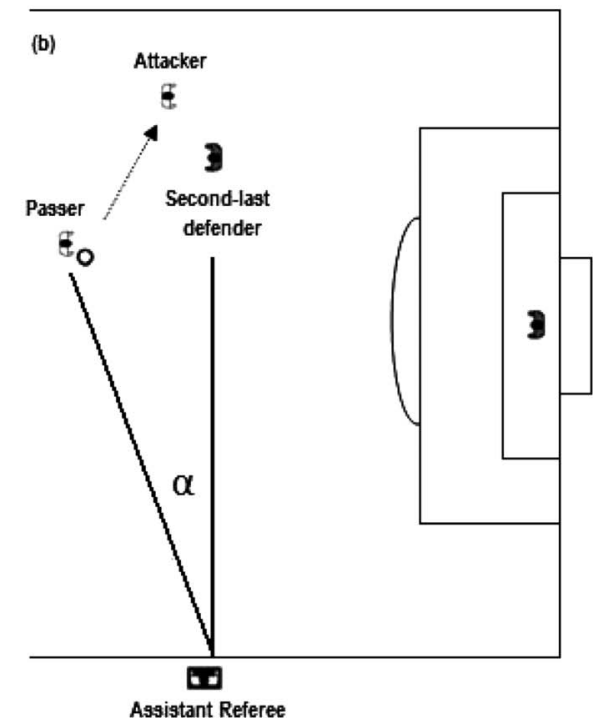

Figure 2. Calculation of the assistant referees' angle of view during (a) offside situations, and (b) onside situations. 
effect of distance, angle of view and match period on the correctness of the decision taken by the officials, the error percentage per category for each variable was calculated. Chi-squared goodness-of-fit tests (Nevill, Atkinson, Hughes, \& Cooper, 2002) were used to examine if the number of decisions and the error percentages were uniformly distributed throughout each category analysis. The meaningfulness of the difference between two means was determined by the effect size, with values of 0.2 , 0.5 and $>0.8$ representing small, medium and large differences, respectively (Cohen, 1998). Significance was chosen at $P<0.05$ for all the statistical tests.

\section{Results \\ Referees}

The total number of foul play incidents was 380, with a mean of $25.3(s=3.7)$ incidents per match. The referees took the correct decision in 326 of the 380 incidents (error percentage: 14.2\%).

\section{Quality of referees' decision in relation to position}

The mean distance of the referee to the incidents was $16.7 \mathrm{~m}(s=7.0)$, with no significant differences $(P=0.74 ; 95 \% \mathrm{CI}:-2.37$ to $1.68 \mathrm{~m}$; effect size: $0.04)$ when making correct $(16.7 \mathrm{~m}, s=7.1)$ or incorrect $(17.0 \mathrm{~m}, s=6.4)$ decisions. In total, 287 incidents $(75.5 \%)$ were awarded in the central area of the field and $93(24.5 \%)$ in the lateral areas. Mean distance to the incidents was greater $(P<0.001$; $95 \%$ CI: 5.30 to $8.27 \mathrm{~m}$; effect size: 1.08$)$ in the lateral areas $(21.9 \mathrm{~m}, s=6.9)$ than in the central area $(15.0 \mathrm{~m}, s=6.2)$. The error percentage in the central area was $13.2 \%(38 / 287)$ and in the lateral areas $17.2 \%(16 / 93)$. The percentage of errors was not uniformly distributed $\left(\chi_{(5)}^{2}=11.14 ; P=0.049\right)$ in relation to the distance to the incidents in the central area of the field (Figure 3). The lowest error rate was achieved when indicating incidents from distances between 11 and $15 \mathrm{~m}$. Distance to the foul plays did not affect the decision making error rate $(P>0.05)$ in the lateral areas of the field.

\section{Quality of referees' decision in relation to match periods}

Distance to the infringements did not increase between halves (first half: $16.3 \mathrm{~m}, s=6.8$; second half: $17.1 \mathrm{~m}, s=7.2 ; P=0.30,95 \% \mathrm{CI}:-2.16$ to $0.66 \mathrm{~m}$; effect size: 0.11 ) and 15 -min periods $(P=0.26)$. The error percentage increased from $9.3 \%(13 / 140)$ to $17.0 \%(25 / 147)$ from the first to the second half in the central area of the field. Figure 4 represents the error percentage for each $15-$ min period in the central area. The calculated value of the

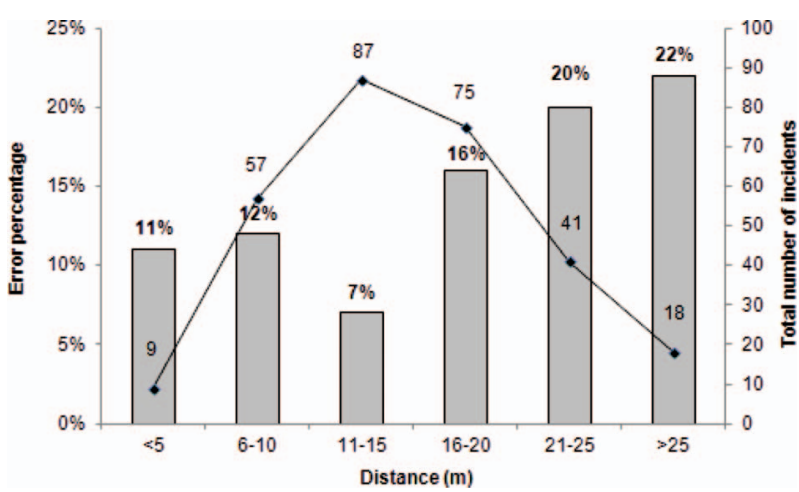

Figure 3. Error percentage and total number of incidents in relation to distance to incidents in the central area of the field.

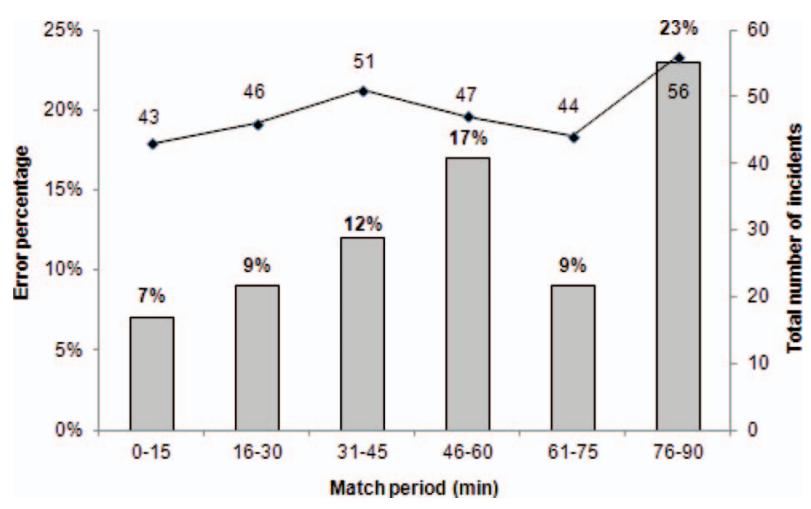

Figure 4. Error percentage and total number of incidents for each of the 15 -min match periods.

chi-squared goodness-of-fit test $\quad\left(\chi^{2}{ }_{(5)}=14.40\right.$; $P=0.013)$ revealed that the error percentage was not uniformly distributed throughout the match, as more incorrect decisions were taken in this area of the field in the last 15-min of the games than in any other 15-min period.

\section{Assistant referees}

We examined 165 potential offside situations, with an average of $11.0(s=5.9)$ situations per match. The number of situations with the attacker in an onside position was $95(88.4 \%$ correct non-flag signals and $11.6 \%$ flag errors) whereas in $70(85.7 \%$ correct flag signals and $14.3 \%$ non-flag errors) situations the attacker was offside. In 71 situations $(43.0 \%)$ the assistant referees flagged and they did not flag in the remaining 94 situations (57.0\%). The overall error rate was $12.7 \%$ (21 of 165 situations).

\section{Quality of assistant referees' decision in relation to position}

The assistants were more frequently $\left(\chi^{2}{ }_{(3)}=37.24\right.$; $P<0.001)$ positioned behind the offside line $(52.7 \%)$ than ahead $(33.3 \%)$ or in line $(13.9 \%)$. As 
shown in Table I, the number of errors was not affected by the position of the assistant referee in relation to the offside line $\left(\chi^{2}{ }_{(3)}=0.86 ; P=0.65\right)$. There were no significant differences $(P=0.65$; $95 \%$ CI: -0.16 to $0.20 \mathrm{~m}$; effect size: 0.07$)$ in absolute distance of the assistant referee to the second-last defender for onside $(0.79 \mathrm{~m}, s=0.54)$ and offside $(0.75 \mathrm{~m}, s=0.66)$ situations. Furthermore, this distance was not different $(P=0.38 ; 95 \%$ CI: -0.15 to $0.39 \mathrm{~m}$; effect size: 0.20 ) between correct $(0.79 \mathrm{~m}, s=0.59)$ and incorrect $(0.67 \mathrm{~m}$, $s=0.59)$ decisions.

The attackers were, on average, $-0.91 \mathrm{~m}$ $(s=0.60)$ behind and $1.13 \mathrm{~m}(s=1.37)$ ahead of the second-last defender in the onside and offside situations, respectively. For the flag errors $(n=11)$ the attackers averaged $-1.03 \mathrm{~m}, s=0.95$ behind the offside line. On the other hand, for the non-flag errors $(n=10)$ the attackers were $0.37 \mathrm{~m}, s=0.38$ ahead of the offside line.

\section{Quality of assistant referees' decision in relation to angle of view}

The angle of view of the assistant referee was wider $\left(P=0.03\right.$; $95 \% \mathrm{CI}:-11.2$ to $1.4^{\circ}$; effect size: 0.34$)$ in the offside $\left(32.2^{\circ}, s=23.1\right)$ than in the onside $\left(25.3^{\circ}, s=18.4\right)$ situations. The frequency of possible offside situations in relation to the viewing angle was not uniformly distributed $\left(\chi_{(5)}^{2}=78.96 ; P<0.001\right)$ as $60.3 \%$ of the situations were judged with angles of view between 0 and $30^{\circ}$. As can be seen in Figure 5, the greatest percentage of incorrect decisions was recorded with angles of view wider than $75^{\circ}$ $\left(\chi^{2}{ }_{(5)}=17.30 ; P<0.01\right)$. There were no significant differences $\left(P=0.38\right.$; 95\% CI: -5.3 to $13.8^{\circ}$; effect size: 0.20$)$ in viewing angles between correct $\left(28.8^{\circ}\right.$, $s=20.7)$ and incorrect $\left(24.5^{\circ}, s=20.6\right)$ decisions.

\section{Quality of assistant referees' decision in relation to match periods}

The percentage of incorrect decisions increased from $8.1 \%(7 / 87)$ to $17.7 \%(14 / 79)$ from the first to the second half of the matches. Figure 6 shows how the error percentage $\left(\chi_{(5)}^{2}=18.65 ; P=0.002\right)$ was not uniformly distributed over the 15 -min match periods. The greatest error incidence was recorded towards the end of the games.

\section{Discussion}

In this study we have examined the effect of positioning on the correctness of the decisions taken by football referees and assistant referees during an elite international tournament. Referees awarded a

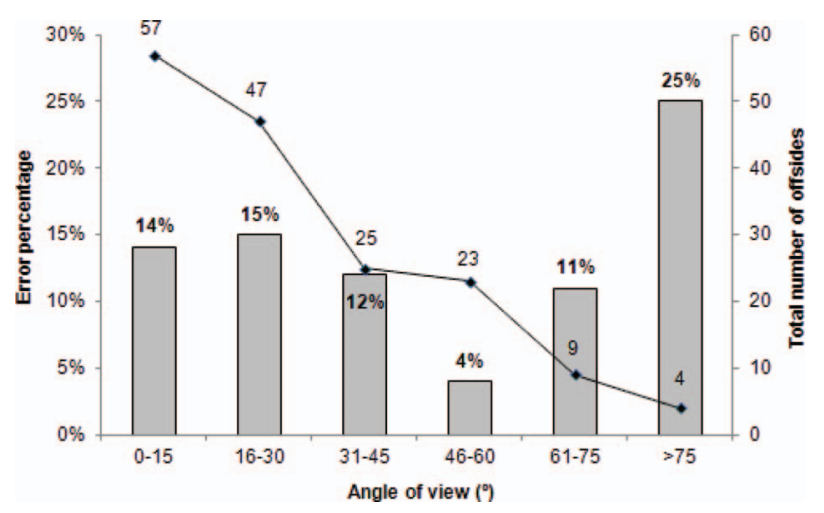

Figure 5. Error percentage and total number of offside decisions in relation to angle of view.

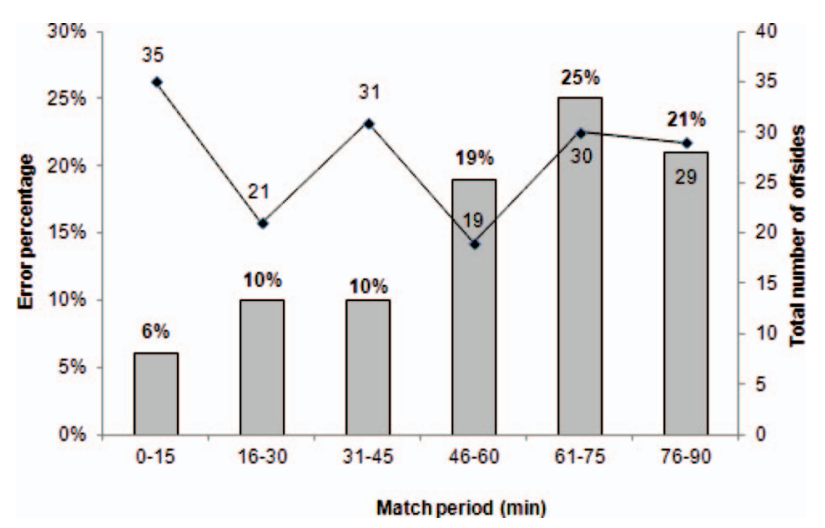

Figure 6. Error percentage and total number of offside decisions for each of the 15-min match periods.

Table I. Decisions of the assistant referees in relation to their position relative to the offside line.

\begin{tabular}{|c|c|c|c|c|}
\hline \multirow[b]{2}{*}{ Decision of the assistant referee } & \multicolumn{3}{|c|}{ Position of the assistant referee } & \multirow[b]{2}{*}{ Total } \\
\hline & In line & Behind & Ahead & \\
\hline \multicolumn{5}{|l|}{ Correct } \\
\hline Flag & $7(4.2 \%)$ & $17(10.3 \%)$ & $36(21.8 \%)$ & 60 \\
\hline Non-flag & $10(6.1 \%)$ & $61(37.0 \%)$ & $13(7.9 \%)$ & 84 \\
\hline \multicolumn{5}{|l|}{ Incorrect } \\
\hline Flag (flag error) & $2(1.2 \%)$ & $4(2.4 \%)$ & $5(3.0 \%)$ & 11 \\
\hline Non-flag(non-flag error) & $4(2.4 \%)$ & $5(3.0 \%)$ & $1(0.6 \%)$ & 10 \\
\hline Total & 23 & 87 & 55 & 165 \\
\hline
\end{tabular}


total of 380 foul play incidents during the matches with an overall error rate of $14.2 \%$. The lowest error percentage in the central area of the field, where the collaboration of the assistant referee is limited, was achieved when indicating the incidents from a distance between 11 and $15 \mathrm{~m}$. In addition, 165 possible offside situations were examined, in which assistant referees presented an overall error rate of $12.7 \%$. Distance of the assistant referee to the offside line did not have an impact on the quality of the offside decision. The risk of making incorrect decisions was reduced when the assistant referees viewed the offside situations from an angle between 46 and $60^{\circ}$. Both referees and assistant referees duplicated the number of error judgments in the second halves of the games.

Match analyses of football officials have traditionally focused on determining the physical demands experienced during the game (Castagna et al., 2007; D'Ottavio \& Castagna, 2001; Krustrup \& Bangsbo, 2001; Krustrup et al., 2002, 2009; Mallo et al., 2009a, 2009b; Weston et al., 2009). The main responsibility of officials is to guarantee the respect of the Laws of the Game and, in particular, Catteeuw, Helsen, Gilis, and Wagemans (2009a) showed role specificity for assessing foul play incidents by referees and for offside decision making by assistant referees. Therefore, an increasing interest has been placed in recent years on the decision making skills of officials during real match play (Catteeuw et al., 2010a, 2010b; Helsen et al., 2006; Oudejans et al., 2005; van Quaquebeke \& Giessner, 2010).

The referees studied during the FIFA Confederations Cup 2009 awarded, on average, 25 foul play incidents per match. This value is slightly lower than the reported averages of 28 and 34-41 incidents per game from other national leagues (Weston, Drust, Atkinson, \& Gregson, 2011b) and international tournaments (Helsen \& Bultynck, 2004; Mallo et al., 2009a), respectively, and can denote a change in the style of refereeing or of the competing teams. To assess physical performance, different studies have examined the distance of the referee to the incidents (Krustrup \& Bangsbo, 2001; Krustrup et al., 2009; Mallo et al., 2007, 2009a) and to the ball (Mallo et al., 2010) to measure the ability to keep up with the play. Nevertheless, at the same time as adopting an optimal positioning, referees must take the correct decision in every situation. In the present study, a panel of expert referees reviewed all the foul plays to assess the quality of the decisions taken by the referees. However, it should be highlighted that the judgement in situ of infringements presents unique stress factors (players and crowd pressure, score, fatigue, previous decisions, etc.) which cannot be experienced by reference panels when replaying the game. Gilis, Weston, Helsen,
Junge, and Dvorak (2006) illustrated these differences as they observed an agreement of only $70 \%$ between match referees and experts panels. Respecting this consideration, the error percentage amounted to $14 \%$ over a total of 380 incidents. To our knowledge, only Van Meerbeek, Van Gool, and Bollens (1987) have previously taken into account the number of correct and incorrect decisions in international tournaments, concluding that $17 \%$ of the decisions awarded by the referees during the FIFA World Cup 1986 were incorrect.

To investigate the factors that may have an impact on the decision making of referees we divided the field of play into two areas. The central area represented the zone that experts from the FIFA Referees' Department encourage the referees to cover during the matches using diagonal movements. On the other hand, the coverage of the lateral areas is influenced by the position of the assistant referees and, therefore, referees were significantly farther from incidents here $(22 \mathrm{~m})$ than in the central area $(15 \mathrm{~m})$. The lowest error rate in the central area of the field was recorded when referees judged the incidents from a distance of 11 to $15 \mathrm{~m}$, whereas the risk of incurring errors increased when referees were more distant from the infringements. In addition, the rate of incorrect decisions in the central area of the field peaked in the last $15-\mathrm{min}$ match period. Altogether, these data suggest that referees should possess an optimal physical capacity to be able to follow the play until the latter stages of the games. Several studies (Krustrup \& Bangsbo, 2001; Krustrup et al., 2009; Mallo et al., 2007) have also shown a significant increase in distance from incidents in the attacking zone during the last $15 \mathrm{~min}$ of the game and variations in the amount of high-speed running and sprinting across a match (Weston, Drust, \& Gregson, 2011a). Complementarily, the incidence that mental fatigue might have on decision making in these final periods of the match is an issue that needs to be further examined. Perceptual-cognitive training tasks have been recently integrated in the training schedule to replicate the demands placed during match play and to improve decision making of referees (Gilis et al., 2006; MacMahon, Helsen, Starkes, \& Weston, 2007; Plessner, Schweizer, Brand, \& O'Hare, 2009). Interestingly, the referees' error rate was higher in the lateral $(17 \%)$ than in the central $(13 \%)$ area of the field of play. It would have been expected that the presence of the assistant referee close to the lateral areas would have facilitated the decision making of the referee. However, our findings suggest that these areas represent a complex scenario when judging the play, as the referee is farther from the situation, whereas the assistant referee needs to control foul plays and simultaneously be facing the second-last 
defenders for offside positions. For this reason, it seems essential to investigate and improve teamwork between officials in the lateral areas of the field, to reduce the risk of making incorrect decisions.

The assistant referees were exposed to a total of 165 possible offside situations during the games, from which 71 were flag and 94 non-flag decisions. On average, every match presented five flag decisions, which is a similar frequency to that reported in other male international tournaments (Catteeuw et al., 2010b; Helsen et al., 2006; Mallo et al., $2009 b)$. The percentage of flag errors (12\%) during the present tournament was similar to that in the 2006 World Cup (10\%; Catteeuw et al., 2010b) and much lower than in the 2002 World Cup (26\%, Helsen et al., 2006).

Recording flag situations is evident in all the studies, however registering non-flag decisions is a controversial matter and reveals a great heterogeneity in the literature. While Helsen et al. (2006) and Catteeuw et al. (2010b) reported frequencies of 0.5 and 4 non-flag decisions per match, respectively, Catteeuw et al., (2010a) and Oudejans et al. (2005) elevated these situations to 24 and 49 per game, respectively. Following recent studies (Catteeuw et al., 2010a) we considered offside situations when the attacking player was $2 \mathrm{~m}$ or less from the offside line. Therefore, we studied an average of six offside non-flag decisions per match, leading to a ratio of flag: non flag decisions of 0.76 , which is in the range of the values obtained in other studies: 0.11 to 6.53 (Catteeuw et al., 2010a, 2010b; Helsen et al., 2006; Oudejans et al., 2005). The error rate during these situations was $14 \%$, which is between previous observations: $4-19 \%$ (Catteeuw et al., 2010a, 2010b). Catteeuw et al. (2010a) reported that five incorrect non-flag decisions were taken per English Premier League match. This is a very high error incidence which reinforces the importance of investigating the factors affecting decision making in these situations.

The position of the assistant referees in relation to the offside line has helped explain the type of error committed by the officials (Oudejans et al., 2000, 2005). In our study, the assistant referees trailed the offside line in $53 \%$ of the cases, led the offside line in $33 \%$ and were in line in $14 \%$, which are similar values to those reported by Oudejans et al. (2005) and Catteeuw et al. (2010b). However, contradicting observations carried out by Catteeuw et al. (2010a), we did not find differences in the number of errors when the assistant referees were ahead or behind the second-last defender. The top-class assistant referees that took part in the present study were selected by the FIFA Refereeing Department as the best standard worldwide and therefore their experience could have led them to adopt a different strategic positioning than national level assistant referees (Catteeuw et al., 2010a). This is supported by the fact that Catteeuw et al. (2010b) did not report differences in the number of correct and incorrect decisions in relation to the position for the assistant referees that took part in the 2006 World Cup. The different frame rate used for match analysis in each investigation may also have influenced the results. The semi-automatic recognition system employed by Catteeuw et al. (2010a) calculated positions every $0.1 \mathrm{~s}$. Therefore, an assistant referee sprinting at a speed of $7 \mathrm{~m} \cdot \mathrm{s}^{-1}$ would travel $70 \mathrm{~cm}$ from frame to frame. In the present study, offside analyses were carried out at $50 \mathrm{~Hz}(0.02 \mathrm{~s})$, which induces a 5-fold higher precision in the measurements. In addition, no significant differences were revealed in distance of the offside line during correct and incorrect decisions, as reported by Helsen et al. (2006).

The angle of view did not seem to affect decision making in offside situations, as we did not detect differences between correct $\left(29^{\circ}\right)$ and incorrect $\left(25^{\circ}\right)$ decisions. In one third of all the situations the angle of view of the assistant referee was less than $15^{\circ}$, which is considered to be within the foveal field (Palmer, 1999). The remaining situations, with angles wider than $15^{\circ}$, are within the peripheral field. The lowest error rate was achieved with angles of view between 46 and $60^{\circ} \quad(n=23)$, whereas viewing angles wider than $75^{\circ}(n=4)$ increased the risk of making incorrect decisions. It could be possible that when the angle formed by the player carrying the ball, the offside line and the attacking player actively involved in the play and subjective to be in an offside position is too wide or to short, the complexity of the analysis increases, whereas medium angles make the situation easier to judge. However, the limited amount of situations suggests that interpretation of these data should be cautious. Previous studies (Catteeuw et al., 2010a) did not detect differences in the number of errors using the same categories of angles. However, in the latter study the viewing angle was calculated between the passer and the second-last defender from the assistant referee's point of view. This definition is adequate for onside situations, where the attacker is behind the offside line, but underestimates the angle of view during offside situations. As the attacking player's position is critical to judge the offside situations, we calculated the assistant referee's angle of view taking into consideration the position of both the defender (onside situations) and the attacker (offside situations). Hereby, the viewing angle of assistant referees in our study was significantly wider during offside than onside situations.

Regarding the temporal distribution of the errors, recent studies (Catteeuw et al., 2010a; Helsen et al., 2006) concluded that assistant referees do not make 
more errors towards the final stages of the matches. However, in our study, offside errors occurred twice as often in the second than in the first half of the matches. Without complementary physical and physiological measurements it is difficult to assess if the observed increment in the frequency of incorrect decisions was due to physical or mental fatigue or a result of tactical changes in the teams as the mach progresses.

From all of the above, we cannot conclude that there is a unique factor responsible for incorrect decisions during offside situations. The interrelation of the variables studied in this investigation together with others such as the number, velocity, trajectories and relative positions of the players, distance of the assistant referee to the players (with possible occlusions) and psychological factors underlying the judgments (score, crowd, pressure) are elements that increase the complexity of the scenario. The limitations of the human visual system to process the information in these complex situations is an additional source of incorrect offside judgments (Baldo, Ranvaud, \& Morya, 2002; Belda Maruenda, 2004; Gilis, Helsen, Catteeuw, \& Wagemans, 2008; Helsen et al., 2006). For instance, on and off the field training sessions that are in line with the physical and perceptual-cognitive demands of the game should be implemented for top-class assistant referees to reduce the number incorrect offside decisions (Catteeuw, Gilis, Wagemans, \& Helsen, 2010c; Catteeuw, Gilis, Jaspers, Wagemans, \& Helsen, 2010d; Catteeuw, Helsen, Gilis, Van Roie, \& Wagemans, 2009b; Gilis, Helsen, Catteeuw, Van Roie \& Wagemans, 2009). Given the high accuracy presented by both referees and assistant referees when judging the play, we suggest that their technical performance should be expressed in the future as a percentage of successful decisions instead of relating it to the number of errors. This consideration can lead to a more positive and optimistic approach to their performance and help them cope with the great pressure they are exposed to during the games.

\section{Conclusions}

The present study showed that top-class international referees experienced a $14 \%$ error rate when judging foul play incidents whereas assistant referees presented a $13 \%$ error rate in offside decisions. Referees reduced the risk of making incorrect decisions when indicating incidents from a distance of 11 to $15 \mathrm{~m}$. The error rate of assistant referees was not affected by their position in relation to the offside line. Angles of view of the assistant referees between 46 and $60^{\circ}$ favoured correct decisions. Both referees and assistant referees increased the risk of making incorrect decisions towards the end of the matches.

\section{References}

Baldo, M.V.C., Ranvaud, R.D., \& Morya, E. (2002). Flag errors in soccer games: The flash-lag effect brought to real life. Perception, 31, 1205-1210.

Belda Maruenda, F. (2004). Can the human eye detect an offside position during a football match? British Medical fournal, 329, 1470-1472.

Castagna, C., Abt, G., \& D’Ottavio, S. (2007). Physiological aspects of soccer refereeing and performance. Sports Medicine, 37, 625-646.

Catteeuw, P., Gilis, B., García-Aranda, J.M., Tresaco, F., Wagemans, J., \& Helsen, W. (2010b). Offside decision making in the 2002 and 2006 FIFA World Cups. Fournal of Sports Sciences, 28, 1027-1032.

Catteeuw, P., Gilis, B., Jaspers, A., Wagemans, J., \& Helsen, W. (2010d). Training of perceptual-cognitive skills in offside decision making. Fournal of Sport E Exercise Psychology, 32, 845-861.

Catteeuw, P., Gilis, B., Wagemans, J., \& Helsen, W. (2010a). Offside decision making of assistant referees in the English Premier League: Impact of physical and perceptual-cognitive factors on match performance. Fournal of Sports Sciences, 28, 471-481.

Catteeuw, P., Gilis, B., Wagemans, J., \& Helsen, W. (2010c). Perceptual-cognitive skills in offside decision making: Expertise and training effects. Fournal of Sport $\mathbb{E}$ Exercise Psychology, 32, 828-844.

Catteeuw, P., Helsen, W., Gilis, B., Van Roie, E., \& Wagemans, J. (2009b). Visual scan patterns and decision making skills of association football assistant referees in offside situations. Fournal of Sport \& Exercise Psychology, 31, 787-797.

Catteeuw, P., Helsen, W., Gilis, B., \& Wagemans, J. (2009a). Decision-making skills, role specificity, and deliberate practice in association football refereeing. Fournal of Sports Sciences, 27, $1125-1136$.

Cohen, J. (1988). Statistical power analysis for the behavioural sciences. Hillsdale, NJ: Lawrence Erlbaum.

D’Ottavio, S., \& Castagna, C. (2001). Physiological load imposed on elite soccer referees during actual match play. Fournal of Sports Medicine and Physical Fitness, 41, 27-32.

Fédération Internationale de Football Association (1993). Laws of the game and universal guide for referees. Zurich: FIFA.

Gilis, B., Helsen, W., Catteeuw, P., Van Roie, E., \& Wagemans, J. (2009). Interpretation and application of the offside law by expert assistant referees: Perception of spatial positions in complex dynamic events on and off the field. Fournal of Sports Sciences, 27, 551-563.

Gilis, B., Helsen, W., Catteeuw, P., \& Wagemans, J. (2008). Offside decision by expert assistant referees in association football: Perception and recall of spatial positions in complex dynamic events. Fournal of Experimental Psychology: Applied, 14, 21-35.

Gilis, B., Weston, M., Helsen, W., Junge, A., \& Dvorak, J. (2006). Interpretation and application of the Laws of the Game in football incidents leading to player injuries. International fournal of Sports Psychology, 37, 121-138.

Helsen, W.F., \& Bultynck, J.B. (2004). Physical and perceptual cognitive demands of top-class refereeing in association football. Fournal of Sports Sciences, 22, 179-189.

Helsen, W., Gilis, B., \& Weston, M. (2006). Errors in judging "offside" in association football: Test of the optical error versus the perceptual flash-lag hypothesis. Fournal of Sports Sciences, 24, 521-528.

Krustrup, P., \& Bangsbo, J. (2001). Physiological demands of topclass refereeing in relation to physical capacity: Effect of intense intermittent exercise training. Fournal of Sports Sciences, 19, 881891.

Krustrup, P., Mohr, M., \& Bangsbo, J. (2002). Activity profile and physiological demands of top-class assistant referees in relation to training status. Fournal of Sports Sciences, 20, 861-871. 
Krustrup, P., Helsen, W., Randers, M.B., Christensen, J.F., MacDonald, C., Rebelo, A.M., \& Bangsbo, J. (2009). Activity profile and physical demands of football referees and assistant referees in international games. Fournal of Sports Sciences, 27, 1167-1176.

MacMahon, C., Helsen, W.F., Starkes, J.L., \& Weston, M. (2007). Decision-making skills and deliberate practice in elite association football referees. Fournal of Sports Sciences, 25, 65-78.

Mallo, J., Navarro, E., García-Aranda, J.M., Gilis, B., \& Helsen, W. (2007). Activity profile of top-class soccer referees in relation to performance in selected physical tests. Fournal of Sports Sciences, 25, 805-813.

Mallo, J., Navarro, E., García-Aranda, J.M., Gilis, B., \& Helsen, W. (2008). Analysis of the kinematical demands imposed on top-class assistant referees during competitive soccer matches. Fournal of Strength and Conditioning Research, 22, 235-242.

Mallo, J., Navarro, E., García-Aranda, J.M., \& Helsen, W. (2009a). Activity profile of top-class association football referees in relation to fitness-test performance and match standard. Fournal of Sports Sciences, 27, 9-17.

Mallo, J., Navarro, E., García-Aranda, J.M., \& Helsen, W. (2009b). Physical demands of top-class soccer assistant refereeing during high-standard matches. International fournal of Sports Medicine, 30, 331-336.

Mallo, J., Veiga, S., López de Subijana, C., \& Navarro, E. (2010). Activity profile of top-class female soccer refereeing in relation to the position of the ball. Fournal of Science and Medicine in Sport, 13, 129-132.

Nevill, A.M., Atkinson, G., Hughes, M.D., \& Cooper, S. (2002). Statistical methods for analysing discrete and categorical data recorded in performance analysis. Fournal of Sports Sciences, 20, 829-844.

Oudejans, R.R.D., Bakker, F.C., Verheijen, R., Gerrits, J.C., Steinbrückner, M., \& Beek, P.J. (2005). How position and motion of expert assistant referees in soccer relate to the quality of their offside judgements during actual match play. International fournal of Sports Psychology, 36, 3-21.
Oudejans, R.R.D., Verheijen, R., Bakker, F.C., Gerrits, J.C., Streinbrückner, M., \& Beek, P.J. (2000). Errors in judging "offside" in football. Nature, 404, 33.

Palmer, S E. (1999). Vision science: Photons to phenomenology. Cambridge, MA: MIT Press.

Plessner, H., Schweizer, G., Brand, R., \& O'Hare, D. (2009). A multiple-cue learning approach as the basis for understanding and improving soccer referees' decision making. Progress in Brain Research, 174, 151-158.

Rontoyannis, A., Stalikas, G., Sarros, A., \& Vlastaris, A. (1998). Medical, morphological and functional aspects of Greek soccer referees. Fournal of Sports Medicine and Physical Fitness, 38, 208214.

Sanabria, J., Cenjor, C., Marquez, F., Gutierrez, R., Martinez, D., \& Prados Garcia, J.L. (1998). Oculomotor movements and football's Law 11. Lancet, 351, 268. .

Van Meerbeek, R., Van Gool, D., \& Bollens, J. (1987). Analysis of the refereeing decisions during the world soccer championship in 1986 in Mexico. In T. Reilly, A. Less, K. Davids \& W.J. Murphy (Eds.), Science and Football (pp. 377-392). London: E \& F.N. Spon.

Van Quaquebeke, N., \& Giessner, S.R. (2010). How embodied cognitions affect judgments: Height-related attribution bias in football foul calls. Fournal of Sport \& Exercise Psychology, 32, 3 22.

Weston, M., Castagna, C., Helsen, W., \& Impellizzeri, F. (2009). Relationships among field-test measures and physical match performance in elite-standard soccer referees. Fournal of Sports Sciences, 27, 1177-1184.

Weston, M., Drust, B., Atkinson, G., \& Gregson, W. (2011b). Variability of soccer referees' match performances. International Fournal of Sports Medicine, 32, 190-194.

Weston, M., Drust, B., \& Gregson, W. (2011a). Intensity of exercise during match-play in FA Premier League referees and players. Fournal of Sports Sciences, 29, 527-532. 